Provided for non-commercial research and education use. Not for reproduction, distribution or commercial use.

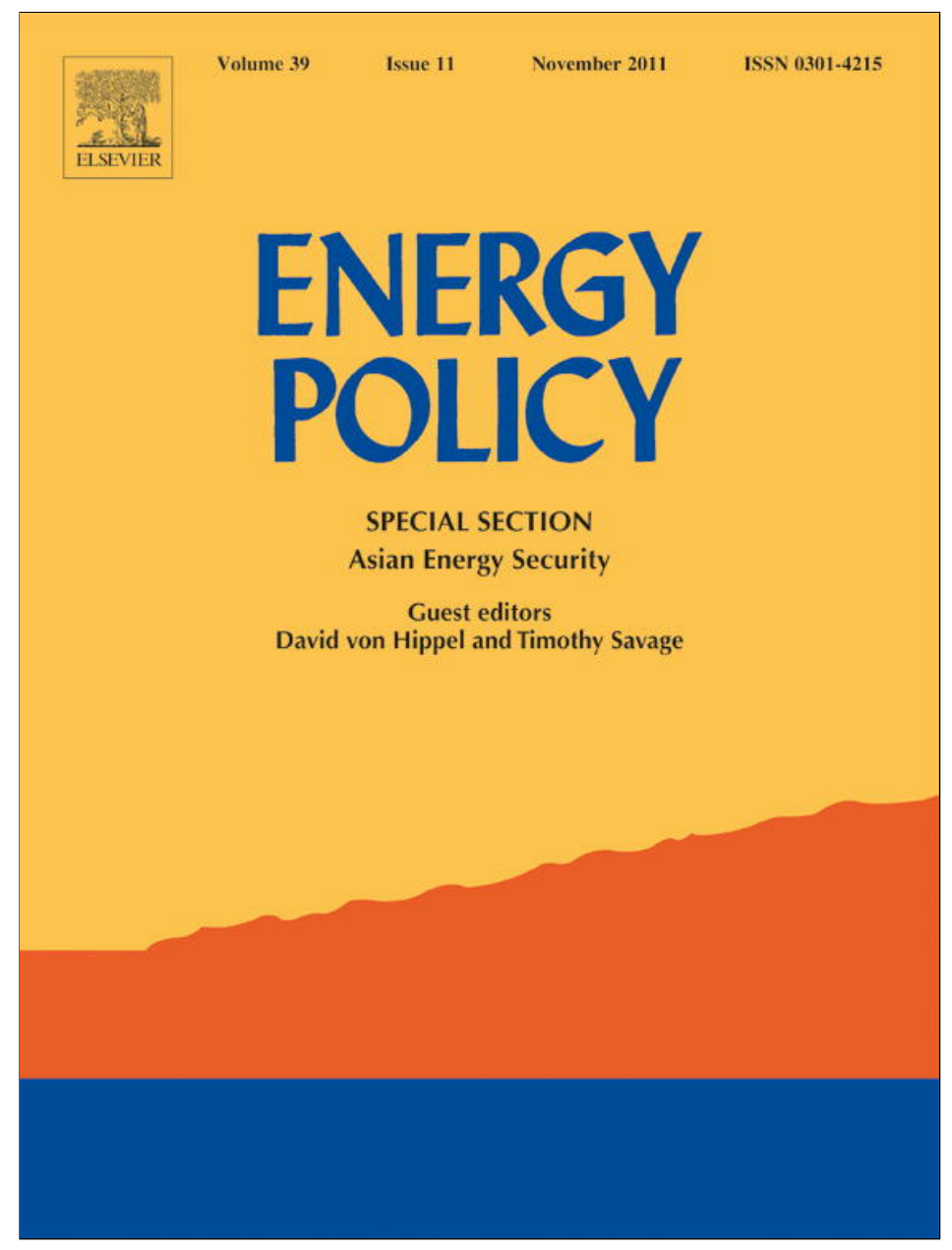

This article appeared in a journal published by Elsevier. The attached copy is furnished to the author for internal non-commercial research and education use, including for instruction at the authors institution and sharing with colleagues.

Other uses, including reproduction and distribution, or selling or licensing copies, or posting to personal, institutional or third party websites are prohibited.

In most cases authors are permitted to post their version of the article (e.g. in Word or Tex form) to their personal website or institutional repository. Authors requiring further information regarding Elsevier's archiving and manuscript policies are encouraged to visit:

http://www.elsevier.com/copyright 


\title{
Reconsidering the European regulation of merchant transmission investment in light of the third energy package: The role of dominant generators
}

\author{
Adrien de Hauteclocque $^{\mathrm{a}, *}$, Vincent Rious ${ }^{\mathrm{b}}$ \\ a Loyola de Palacio Chair in European Energy Policy, European University Institute RSCAS, 19 Via delle Fontanelle, 50014 San Domenico di Fiesole, Italy \\ ${ }^{\mathrm{b}}$ Microeconomix, 5 rue du Quatre Septembre, 75002 Paris, France
}

\section{A R T I C L E I N F O}

\section{Article history:}

Received 29 October 2009

Accepted 8 August 2011

Available online 7 September 2011

Keywords:

Merchant transmission investment

European Union

Third energy package

\begin{abstract}
A B S T R A C T
The regulation of merchant transmission investment (MTI) has become an important issue in the EU electricity sector, subsequent to the granting of authorizations by European authorities to five merchant projects: BritNed, Estlink, the East West Cables, NorGer and recently a merchant line connecting Italy and Austria. The creation of a new Agency for the Cooperation of Energy Regulators (ACER) at the EU level, which has decision-making powers on MTI, therefore presents a unique opportunity to question and re-design the current European policy. This paper shows that the recent decisions concerning MTI may suffer a strong bias against dominant electricity generators while incumbent Transmission System Operators (TSOs) or new entrant TSOs are generally favored by national regulators and the European Commission (EC). This strategy is misguided as it fails to recognize both the new incentives of generators to develop MTI and the conflict of interest between the regulated and non-regulated activities of incumbent TSOs. Letting dominant generators undertake MTI is indeed generally beneficial as long as potential abuses of dominance are mitigated. To deter possible anti-competitive effects, we propose a new and feasible allocation of regulatory powers based on a clear demarcation between the market monitoring powers of ACER and the antitrust powers of the EC.
\end{abstract}

(c) 2011 Elsevier Ltd. All rights reserved.

\section{Introduction}

Merchant transmission investments (MTI) are profit-motivated investments in cross-border infrastructure undertaken by non-regulated market players. Contrary to regulated transmission investments remunerated with a regulated access tariff, MTI are remunerated by the congestion rent ${ }^{1}$ arising from the spot price differential between the export and import zones, or by the sale of Financial Transmission Rights (FTR) in certain markets. MTI are often thought of as an acceptable second-best solution when regulated investment fails to develop at a suitable pace (Brunekreeft, 2005; Brunekreeft, Neuhoff and Newbery, 2005; Littlechild, 2003; Joskow, 2006). They however create a welldefined regulatory trade-off. On the one hand, they might indeed help address a perceived problem of under-investment. On the other hand, they lead to a partial un-regulated monopolization of the network, which increases the risk of anti-competitive effect (e.g. network foreclosure), all the more when the MTI investor is a

\footnotetext{
* Corresponding author. Tel.: +352 661835 613; fax: +35243032592.

E-mail address: adrien.dehauteclocque@eui.eu (A. de Hauteclocque).

${ }^{1}$ Congestion rent is the difference between the prices of electricity in the importing and exporting zones multiplied by the volume of exchange. The origin of congestion rent is thus the difference in electricity prices between these two zones provoked by congestion. As a remainder, differences in electricity prices exist when there is not enough transmission capacity to transport cheap energy; i.e. when there is congestion.
}

dominant generator in one of the related markets. This paper aims to investigate this trade-off in the specific context of the European Union (EU).

To regulate MTI efficiently, it is required that the regional market designs be harmonized and that the cross-border regulatory framework be robust. A single regulator enjoying wideranging market monitoring (on the use of both generation and transmission capacities) and sanction powers will facilitate detection and deterrence of anti-competitive behavior. The example of the USA shows that a robust regional regulatory framework eases the development of MTI (Joskow, 2006). Most liberalized power markets in the USA have been (or are about to be) able to implement FTR. This opened the possibility for a decentralized development of MTI rewarded through the sale of the FTR that new MTI create for the system as a whole (Hogan, 1992, 2002). ${ }^{2}$ This framework also has the advantage to avoid regulatory bias against dominant generators since regional supervision by the federal regulator and the Market Monitoring Unit is more likely to detect market abuse. This is important as low-cost generators

\footnotetext{
${ }^{2}$ FTR between two given nodes in a power system with nodal pricing allows holders to receive the nodal price difference at these two nodes. FTR can thus be used as financial tools to hedge against locational price differences. This sets the value of FTR. Rather than receiving the price difference at both ends, a MT investor can then sell the FTR it creates for the system to other market participants.
} 
may have strong incentives to push for the development of welfare-increasing transmission investment (Sauma and Oren, 2009). Big consumers or suppliers with a net buying position may also have incentives to push for the development of MTI to debunk zones with high market power (Meade, 2005).

Contrary to the USA, Europe is an example of a weak regulatory framework with a bias against the direct participation of generators in the development of MTI. Without effective market monitoring, the market and anti-competitive behaviors are not monitored on an on-going basis but only in case of extreme events (for instance the price spike in France-CRE, 2008 and 2009). Implementing FTR is still hard in Europe for three reasons. First, national market designs are not harmonized enough, even if they are increasingly converging through market coupling. Second, regulatory supervision over cross-border infrastructure is insufficient. Third, it is not a priority for the moment even if it is planned (ENTSO-E, 2010a,b).

Until recently, MTI was considered a relatively minor issue in Europe. This has changed subsequent to the authorizations granted by European authorities to several merchant projects: the interconnector Estlink between the Baltic and Nordic electricity markets, BritNed between the UK and the Netherlands, the two East West Cables between North Wales and the Republic of Ireland, NorGer between Norway and Germany and a merchant line planned by an Italian new entrant in generation, named Eneco Valcanale, to connect Italia and Austria (between Tarvisio and Arnoldstein). The small number of accepted projects so far does not display a clear picture of the strategy of the EU for MTI, except for a general reluctance to let dominant generators and suppliers undertake MTI (or obtain long-term priority access rights to interconnection through MTI promoted by a third party). This is well summed up in the most recent note of the European Commission (EC) on this issue: "Exemption requests by dominant undertakings in markets served by the new infrastructure are likely to have the greatest potential for harming competition and therefore require particularly careful scrutiny" (DG TREN, 2009). To the opposite, even weakly unbundled Transmission System Operators (TSO) seem to be favored. This paper aims to discuss this twofold trend in light of the on-going changes in the regulatory framework brought up by the so-called Third Energy Package of September 2009.

The Third Energy Package is the third EU package of legislation (Directives and Regulations) on the internal electricity and gas markets enacted to push forward the completion of the single energy market. ${ }^{3}$ It is fully applicable since March 2011. The three main changes brought by the Third Energy Package are: (i) strengthening unbundling of transmission assets from supply activities, (ii) enhancing the national regulators' powers and creating an Agency for the Cooperation for Energy Regulators (ACER) with limited competences on MTI and (iii) increasing market transparency by a set of measures on disclosure of posttrade data and record keeping. The Third Energy Package considerably modifies the regulatory landscape as it starts to unify energy regulatory oversight at the European level. As a consequence, it may open new opportunities for a smarter EU energy policy on MTI.

This paper aims to propose feasible improvements to the EU regulatory regime for MTI. It will argue that the current suspicion towards generators is misguided if Europe can rely both on the new powers of supervision of ACER and on an aggressive antitrust policy by the EC. In Section 2, we will present the European regulatory regime for MTI and the current bias against generators.

\footnotetext{
${ }^{3}$ The first legislative package for electricity was enacted in 1996 and the second in 2003.
}

Section 3 will conduct a comparative analysis of generators and (often weakly unbundled) TSOs as MTI investor in the European context. Section 4 will analyze how to articulate market monitoring by ACER and antitrust policy by the European Commission (EC) in the case of MTI.

\section{The European bias against dominant generators as merchant transmission investors}

This section first presents the EU regulatory regime for MTI and the changes brought by the Third Energy Package. It then analyzes recent decisions and policy trends to show that a bias against dominant generators can be seen.

\subsection{The EU regulatory regime for MTI under the second and third energy packages}

Since the second legislative package of 2003 entered into effect, private operators may obtain authorizations to undertake MTI from national regulatory authorities (NRA) and the EC for highly risky interconnection projects. ${ }^{4}$ To be authorized, a merchant project must obtain exemptions from certain key requirements of EU electricity law, in particular regulated third-party access (TPA) and the use of the collected congestion rent. This is Article 7 of Regulation 1228/2003 on cross-border exchanges which organizes the exemption process and similar rules exist in the Third Energy Package. In theory, an exemption can only be granted if the conditions set out in Art. 7(1) are met. These conditions address, among other things the impact of the project on competition and network externalities, and the level of risk involved or its legal form. According to the risk involved, national and European authorities can grant full or partial exemptions for a duration to be defined on a case-by-case basis. These exemptions mainly concern direct-current interconnectors, but alternating-current interconnectors may also be considered, in exceptional circumstances.

Until the effective implementation of the Third Energy Package in March 2011, the NRAs of the Member States directly involved had jurisdiction over the granting of the exemption. The merchant investor thus had to submit applications to each national regulatory authority. And the national regulatory authority could ask for additional conditions, for instance on the duration of the exemption and the allocation of capacities, so that they effectively grant the exemptions. The Member States or the NRAs in charge thus had to cooperate and find common grounds for the grant of the exemption. In the case of a sustained disagreement between them, the project could not proceed. If they agreed, the $\mathrm{EC}^{5}$ retained the right to propose amendments or to completely withdraw the exemption.

The Third Energy Package (marginally) alters this allocation of decision-making powers. NRAs remain in charge of the examination of applications but can jointly decide to delegate their power to ACER. They are also required to notify ACER and the EC as soon as they receive a new exemption application and inform them of their common decision. The innovation lies in the fact that ACER is to take a final decision in case of a sustained disagreement between the NRAs involved. ACER thus constitutes an additional forum where decisions may be more easily taken in the common interest of the EU. However, Member States may still provide for the NRAs or ACER to submit an opinion on the application to the

\footnotetext{
${ }^{4}$ In theory, regulated projects undertaken by national TSOs should thus remain the rule and MTI the exception.

${ }^{5}$ The EC Competition Directorate (DG COMP) may assist the Energy Directorate (DG Energy, former DG TREN) for the competition analysis of exemption applications (see Talus, 2006).
} 
relevant body in the Member States for formal approval. The final decision can thus be retained by Member States. In event of refusal by ACER, its decisions may be appealed before the European Community Courts. In the case the NRAs or ACER reach a positive decision, the EC will be able to request them to amend or withdraw the decision and the notifying entities are required to comply. The EC however is still not granted the power to overrule Member States and NRAs in case they agree on rejecting the application.

Overall, ACER creates an institutionalized forum for cooperation but is vested with only a limited degree of discretionary power that essentially limits its action to "sunshine" regulation (Henry, 1997; Henry et al., 2001). ACER primarily has a monitoring and advisory role. Its main task is to provide opinions and recommendations to TSOs, NRAs, the EC, the Council and the European Parliament. These opinions and recommendations should contribute to ensuring greater coordination among TSOs and regulators of the different Member States, spreading good practices and promoting harmonization in the implementation of the new Directives and Regulations within national law. As we will see in the remaining of this paper, the role of ACER within MTI regulation may accordingly become stronger on market conduct post-investment that on the decision to grant authorizations ex ante.

\subsection{MTI as a 'TSO business' in Europe?}

The granting of exemptions to the Estlink, BritNed, the East West Cables, NorGer and the new merchant line connecting Italy and Austria in the last few years demonstrates that a new interest for MTI is growing in the marketplace. It also demonstrates that NRAs, like the EC, seem increasingly favorable to this new way of pushing forward the development of interconnection. MTI might even become one of the only effective and achievable ways of developing the cross-border network. ${ }^{6}$ The design of MTI regulation, however, remains a major challenge for EU energy law and regulation. This is why the EC has already published two documents to clarify its enforcement policy (DG TREN, 2004, 2009). The French regulator CRE and the UK TSO National Grid also launched public consultations on MTI in May and July $2010 .^{7}$

The important question here is to understand who will be allowed by the EC and NRAs to invest in merchant lines. Pursuing a competition analysis of an exemption application requires first and foremost looking at who the applicant is and to whom the capacity will be allocated. What matters most is who the contractors are; dominance thus tends to matter more than market behavior because the competitive effect of a given business conduct is generally dependent on the extent of market power. Even if the identity of the potential recipients of exemptions does not flow automatically from Art. 7 of Regulation 1228/2003, recent experiences seem to indicate that both incumbent TSOs and pure new entrant $\mathrm{TSO}^{8}$ will be granted exemptions provided they meet the other criteria of Regulation 1228/2003. ${ }^{9}$ We observe that BritNed, which links the network of Great Britain and the

\footnotetext{
${ }^{6}$ It is worth noting that merchant interconnection (whether built by generators or not) alone will not fix the lack of cross-border capacity in Europe. This is because the available capacity of some interconnections is constrained by bottlenecks on inner national lines. Relieving this congestion requires solving the enduring problem of transparency on the location of network congestion within national network (DG COMP, 2007). This problem is however beyond the scope of this paper.

${ }^{7}$ See CRE (2010) and NG (2010). Note that the British consultation only concerns use of system charges applied on (exempted) interconnectors.

${ }^{8}$ We call 'pure' new entrant TSOs a company, which does not hold any business interest in generation or retail in the markets linked by the interconnector, and which did not previously own any network assets.

${ }^{9}$ We note that the conditions for exemption in Regulation 714/2009 are strictly similar to the conditions set in Regulation 1228/2003.
}

Netherlands, was granted an exemption even though it is owned by a subsidiary of both the British TSO National Grid and the Dutch TSO Tennet. Similarly, the two East West Cables intended to link the network of Great Britain and the Republic of Ireland will be owned by a pure new entrant TSO and received an exemption. In contrast, the situation is likely to be different for generators. Merchant lines are very capital-intensive. It is thus unlikely that a true and small new entrant in generation will be able to carry out such a project, except as part of a consortium. It is the case for NorGer where Agder Energi and Lyse are generation companies with no dominant position in Germany or Norway (neither elsewhere). The two other shareholders in the NorGer project are the Swiss energy trading company EGL and Statnett the Norwegian TSO (that entered lately into the project). The merchant line between Tarvisio and Arnoldstein that Eneco Valcanale develops to connect Italy and Austria is an exception because it is a fairly small project ( 28 million Euros only). ${ }^{10}$ These situations and similar ones would not create competition problems. The remaining uncertainty therefore concerns the right of dominant generators to undertake MTI and participate in the open seasons of TSOs. ${ }^{11}$ While it is true that the Estlink cable between the Baltic and Nordic markets involves two incumbent generators from both sides, this project instead follows a security of supply rationale ${ }^{12}$ aiming to limit the Baltic States' dependence on Russia. It cannot be considered as a full commercial project (Piebalgs, 2008). Moreover, the exemption is only 5 years as compared to 20-25 years in the other cases and the project will recover a regulated status in $2013 .^{13}$ The following points also tend to show that dominant generators will be prevented from investing in merchant lines, at least on a fully commercial basis.

First, DG TREN has clearly stated in its interpretative note of 2004 that "it will be expected that exemptions cannot apply where an existing dominant position is created or reinforced or where the granting of an exemption reduces the scope for diluting existing dominant positions". The note then goes on as follows: "With regard to the requirement that the investment must enhance competition in electricity (gas) supply, it is difficult to conceive of a case where an exemption could be granted to a new piece of infrastructure that was wholly or partly owned, controlled or likely to have a significant amount of its capacity allocated to a dominant player in one of the markets affected." This has been clearly restated in the last interpretative note of the EC (DG TREN, 2009). In the gas sector, where we have more experience, exemptions have indeed only concerned non-dominant players, except for transcontinental pipelines. Some national regulators, for instance the Italian AEEG, have also

\footnotetext{
${ }^{10}$ The cost of the project is limited for two reasons. First, it is a $12 \mathrm{~km}$ line only. Second, it is developed with the Alternative Current (AC) technology that is far cheaper than the DC technology classically used to build merchant lines. The AC technology can be used here because the connection is an overhead one and is quasi-radial. (Source: http://www.daviso.com/en/press-release/eneco-valcanale-s viluppa-la-prima-merchant-line-europa, consulted 30 July 2011).

${ }^{11}$ DG TREN (2004) states: "Normally it will be expected that developers seeking exemptions will have, as far as possible, given other parties an opportunity to gain access to the new facility at the planning and feasibility stage, for example through an open season procedure. Alternatively, developers should create the possibility for a minimum level of third party access to the new infrastructure under the rules of the Directive for a certain proportion of its capacity." Open season is thus a form of TPA access. ERGEG follows this interpretation (ERGEG, 2007a). The EC later also emphasized the role of open season as a device to test market demand for transmission, as with the Nabucco pipeline (DG TREN, 2009). On good practices for open season, see ERGEG (2007b). The 'alternative' option is auctions for long-term reservations (so without equity investment).

${ }^{12}$ We note that the security of supply rationale was important for the Baltic states but that for Nordic states the objective was mainly to obtain cheaper electricity from Estonia.

${ }^{13}$ The cable will then be re-purchased by the TSOs and become a regulated infrastructure project.
} 
repeatedly stated that dominant firms will not in principle obtain exemptions.

Second, for already existing and amortized interconnectors with long-term priority access rights owned by dominant firms, the EC and the European Court of Justice (ECJ) have been particularly rigid with dominant operators. They systematically deemed long-term priority access rights signed before liberalization to be abuse of a dominant position and required that $100 \%$ of capacities be freed up (e.g., on the UK-French submarine interconnector, the Dutch-German interconnector as well as on the Norway-Denmark and Denmark-Germany interconnectors following the merger $V E B A / V I A G)$. The same applies to the prolongation of pre-liberalization access contracts beyond their originally scheduled end date when this possibility was foreseen in the historic contract (Nyssens and Schnichels, 2007).

Third, the EC is currently using its power under the EU antitrust laws to force dominant incumbents to divest their transmission arms. In 2008, both E.ON (in the electricity sector) and RWE (in the gas sector) in Germany accepted divestitures to avoid further antitrust scrutiny. It is thus hard to imagine the EC supporting dominant generators who would like to privately monopolize the network through MTI while pursuing this antitrust policy.

In the current context, a strong suspicion against dominant generators is displayed, especially as regards their vertical integration in transmission. It is therefore most likely that the incumbent generators will be excluded from the exemption process and that MTI will be restricted to dominant and new entrant TSOs, with or without open seasons, except in specific cases such as Estlink. The remaining sections of this paper will show that the current regulatory choices, if they are confirmed, are largely misguided. Indeed, once the principle of MTI is accepted, the incentive scheme of the different market players changes and so does the competitive effect of their market conduct on welfare.

\section{TSO vs. generator as merchant transmission investor: Review of the literature and application in the European context}

This section first shows that restricting MTI to TSOs, in particular incumbent TSOs, is likely to yield limited efficiency gains due to the risks of under-sizing of new lines and abuse of dominance. It then argues that allowing dominant generators to invest in merchant lines is likely to be a superior solution in most cases.

\subsection{MTI as a 'TSO business' leads only to limited efficiency gains}

MTI undertaken by TSOs, especially incumbent TSOs, are unlikely to substantially improve welfare compared to the current situation. They will have potentially strong perverse effects on competition for the three following reasons. ${ }^{14}$

First, MTI by new entrant or incumbent TSOs generally leads to under-sized transmission investment with a capacity around half the optimal level (Stoft, 2006). Because the rationale of allowing MTI is to increase cross-border capacity and thus competition, this is a major drawback. ${ }^{15}$ This is actually acknowledged by the

\footnotetext{
14 Only the first consequence applies for new entrant TSOs.

${ }^{15}$ This argument assumes that 'perfect' competition for the development of the network does not exist (in which case welfare would be maximized). This is indeed the case in practice mainly because of indivisibility and economies of scale constraints, which make a second merchant investment in the same cross-border transmission market unlikely and most of the time infeasible in the short to medium term. Other reasons such as the difficulty to obtain exemptions and the small number of potential investors (given the risks involved) also contribute to
}

EC as one of the most serious issues in the regulation of MTI (DG TREN, 2009). Merchant investors define the size of the line so as to maximize profit through the collected congestion rent while the transmission capacity is optimal (from a social welfare point of view) when the total cost of the system is minimal, i.e. when generation and transmission costs are jointly minimized. When generation and transmission costs are minimized, congestion rent is far smaller than when the merchant TSO investor maximizes profits (see Fig. 1). BritNed is a good example of a situation where the TSOs either alone or with the agreement of regulators finally opted for transmission capacity that maximizes the congestion rent (see Brunekreeft and Newbery, 2006). Even the EC acknowledged that it had probably happened in the case of BritNed and consequently imposed a regulatory review of the economics of the project after ten years of operation (DG TREN, 2009).

Second, the current policy gives incentives to incumbent TSOs to build merchant lines instead of regulated lines. This represents a new opportunity given to incumbent TSOs to abuse market power (Joskow, 2006). Indeed, performance-based regulation forces TSOs to build (regulated) transmission capacity close to the optimal level, which limits rent extraction. A TSO willing to extract a maximal (congestion) rent is thus likely to choose a merchant investment, even if the capacity is far from optimal from a social welfare point of view (Gence-Creux, 2010).

Lastly, an incumbent TSO is likely to have incentives to manipulate the dispatch of electricity flows so as to increase profits on the merchant line. ${ }^{16}$ The TSO may also have fuzzy incentives to deal with the possible network externalities created by merchant lines in the best interests of society. The sixth criterion of Article 7 of Regulation 1228/2003 on cross-border exchanges (retained in the Third Package) is intended to prevent transmission investment with negative externalities. Transmission investment can indeed potentially generate negative externalities and then be detrimental to the whole power system (Bushnell and Stoft, 1996). It is complicated to apply, however, as there are asymmetries of information between the TSO and the regulator. The incumbent TSOs are the only ones to have sufficient expertise to measure negative effects of new transmission investments on network security and may thus abuse their dominant position by refusing competing merchant projects on false grounds. The inherent conflict of interest existing when regulated TSOs are allowed the opportunity to invest in merchant lines may lead to unequivocal, but hardly detectable, discrimination against new entrants. ${ }^{17}$ For these reasons and to avoid socially detrimental loop flow effects, MTI should at least be strictly restricted to direct current (DC) lines in Europe. ${ }^{18,19} \mathrm{We}$ note here that the EC seems to be of the same opinion when it states that "it [is] difficult to conceive of exemptions for $A C$

\section{(footnote continued)}

create imperfect competition conditions. Consequently, it is even more important for regulation to ensure that the incentives of merchant transmission investors are aligned as closely as possible with social welfare.

${ }^{16}$ If the Independent System Operator (ISO) model is imposed, i.e. that the system operator is not the transmission owner, this conflict of interest disappears. The owner of the network assets should then be allowed to develop MTI (Brunekreeft, 2005). However, this model has little chance to be legally imposed in Europe in the near future.

${ }^{17}$ A possible solution is again to rely on the ISO model.

18 Radial or quasi-radial AC interconnections can also be MTI with no problem of loop flows. This could be the case for the two new merchant lines from Switzerland to Italy (Cariello, 2008) and for the new merchant line from Slovenia to Italy (Source: http://www.enel.com/en-GB/media/news/merchant_line/index. aspx).

${ }^{19}$ This is because power flowing through DC lines can be directly controlled with power electronics while power flowing through classical AC lines can be controlled only through the re-dispatch of generation and load. 


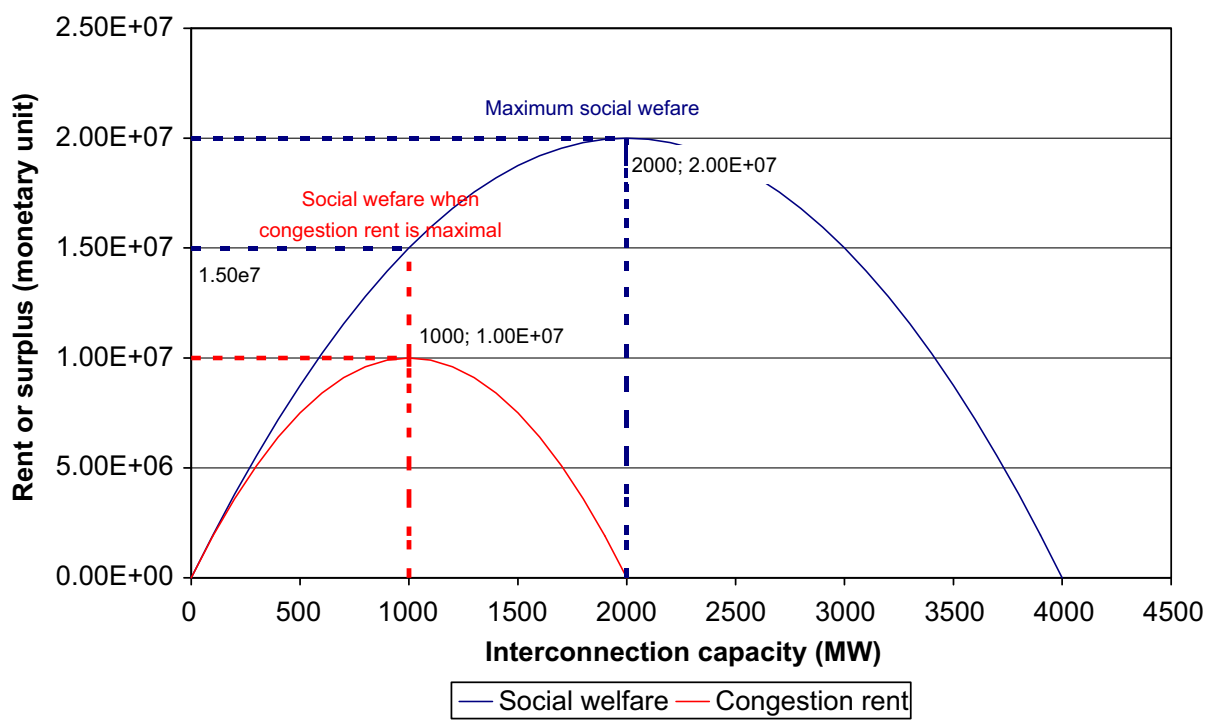

Fig. 1. An example of variation in congestion rent and social welfare according to the interconnector capacity between two zones for linear demand and supply curves (own calculus).

interconnectors which are subject to unattributable loop flows" (DG TREN, 2004).

A strategy relying on MTI built primarily by TSOs thus does not appear satisfactory. It is striking to see that the EC in fact acknowledges the possible conflict of interest between the regulated and non-regulated activities of incumbent TSOs. The EC indeed states that if a merchant line must be "separate at least in terms of its legal form from the system operators in whose systems that interconnector will be built", it is because it aims to ensure "sufficient ring-fencing of non-regulated activities of TSOs" (DG TREN, 2009). However, the EC does not draw the full conclusions and hence advocate for ownership unbundling of national networks and MTI, as it usually does for the unbundling of network and supply activities in domestic markets.

\subsection{Incentives for generators to build MTI in Europe}

By preventing dominant generators from investing in MTI, the EC does not take into account the window of opportunity created by the ongoing changes in cost conditions currently occurring in European energy markets. These changes have given strong incentives to some generators to invest and build merchant lines. On the one hand, some countries and energy companies are committing to a renaissance of the nuclear technology. On the other hand, the costs for fossil fuels are thought to be following a rising and volatile trend in the medium to long term even if projections are uncertain (EIA, 2011).

This situation will result in classic opportunities for arbitrage between countries with different mixes of generation technologies. The rebirth of nuclear energy in some countries (despite the Fukushima accident) will give an advantage to their national operators while renewable energies in other countries will not suffice to cover the needs of power (DG TREN, 2008). In chronological order, Finland, France have announced their willingness to allow the construction of new nuclear power plants. Utilities with the nuclear advantage may then want to export to compete against local incumbents who are more dependent on fossil fuels and renewables. In addition, because national decisions to re-launch atomic energy programs are not simultaneous, there may even be inter-temporal arbitrages between countries favorable to nuclear power. These changes in cost conditions have combined to create new incentives for dominant generators (and some big industrial consumers) to undertake MTI and secure their generation investment by contracting abroad.

\subsection{Under-sizing of MTI built by generators}

MTI built by generators may also suffer from under-sizing. The extent of under-sizing depends on the generator's exercise of market power. Generators with low costs have strong incentives to export power in zones where prices are set by thermal plants with high marginal costs. However, generators must balance these incentives against the effect of increasing interconnection capacity on their market power on both sides of the line. Similarly, large consumers (e.g. suppliers integrated with generation) in importing zones have also incentives to build merchant line to import cheap energy. The rationale is symmetric to the case with a cheap generator in an exporting zone. First, we consider a situation where the generator has no market power, neither in the zone where it is located nor in the destination market. Next, we will consider the opposite situation studied by Sauma and Oren (2009), i.e. when the generator is dominant in its domestic area (not an unrealistic situation in the European Union) and willing to develop a MTI. This situation is what some European utilities are indeed considering. It is the case for instance of EDF that sees MTI as a way to optimize its generation portfolio (Edwards, 2010). ${ }^{20}$

Let us consider the situation of a cheap generator in a zone where there is no market power ${ }^{21}$ (because of strong regulatory scrutiny, for instance). This generator has the right incentives to build a merchant line with an optimal capacity. To explain this, note that its profit function is the sum of the revenue earned both in its home and destination market, minus the sum of its generation investment costs, operational generation costs and transmission investment costs. As we assume that this cheap generator has no market power, it cannot influence revenue.

\footnotetext{
${ }^{20}$ The implication of Adger Energi and Lyse in the NorGer project show that other generators are indeed interested in securing access to interconnection. As far as the Italian companies Eneco Valcanale and in the future Enel are concerned, they are in the situation of suppliers importing electricity in a high price zone.

21 There is also the case of a generator with no market power in the fringe of a monopoly in an export zone willing to invest in transmission. At worst, this generator without market power then invests as the generator with market power would do (cf. Sauma and Oren, 2009 and next paragraph).
} 
The objective is thus only to minimize costs. When generation and transmission investment decisions are integrated, the generator behaves as a benevolent integrated utility. As a consequence, a cheap generator within a zone that has no market power will choose an optimal capacity for the merchant line from the social welfare point of view. The same rationale applies for a consumer in an importing zone with no market power. To maximize its utility, it will minimize total cost and behave as a benevolent integrated utility, and so opt for the optimal capacity for the merchant line (from the social welfare point of viewMeade, 2005).

Now we consider the situation of a cheap generator with market power. Sauma and Oren (2009) studied what the incentives are for generators to support transmission investment in this situation. They consider a two-node network with one generator and load at each node. Only one node has access to cheaper generation. Each generator can use its market power and can thus behave as a monopoly with respect to residual demand when its zone is isolated by congestion. Sauma and Oren (2009) also studied the incentives for generators to undertake transmission investment for small values of capacity when congestion and pure passive-aggressive Nash equilibrium exist. ${ }^{22}$ In this framework, Sauma and Oren (2009) showed that a net exporting generator has all the more incentive to fund socially efficient transmission investment that it holds more of the property rights on the new line. Indeed, this generator is more likely to sacrifice profit from market power in order to increase the profits it receives from the transmission property rights it holds. Similarly, a large buyer of power (generally a supplier vertically integrated in generation) in an importing zone is more likely to sacrifice utility from monopsony power to increase the rent it receives from the transmission property rights it holds.

The analysis done by Sauma and Oren (2009), however, does not provide firm conclusions on whether under-sizing is worse in the case of a dominant generator or in the case of a TSO. The analysis of Sauma and Oren (2009) does not consider the range of values for transmission capacity where the network is still congested and no pure Nash equilibrium exists, while the capacity of an MTI built by a TSO seems to be in this range. Nevertheless, there is a presumption that under-sizing will be alleviated when the investment is undertaken by a generator because it avoids a double marginalization problem (the generator and the MTI exerting distinctly their market power otherwise). Besides, we will see in the next section that other benefits also accrue.

\subsection{The other benefits of MTI built by dominant generators}

If dominant generators are authorized to build merchant lines in Europe, beneficial impacts may go beyond our first analysis of social welfare. Of course, merchant lines promoted by dominant firms retain the usual positive effects of any new increase in interconnection capacity, especially with respect to security of supply and ultimately on the political goal of a deeper integration of the European single market. In this subsection, we show that other benefits may be expected, especially concerning generation investment with high fixed cost technologies.

First, a welfare-increasing effect emerges because generators may have more information than TSOs on opportunities to arbitrage between national markets. TSOs tend to stay within their national or regional boundaries while generators are increasingly present in a number of national markets through mergers and

${ }^{22}$ Sauma and Oren also examined the case where transmission capacity is high enough so that a Nash-Cournot equilibrium exists and the network is not congested. Obviously, in this situation generators have no incentives to invest in transmission capacity because increasing capacity does not change their benefits. acquisitions. Generators may thus have a better understanding of the evolution of market conditions than TSOs and better anticipate future price differentials. Generators might better be able to uncover new opportunities for MTI.

The second welfare-increasing effect is probably the one that has the most consequences because it is related to investment in generation. Some generators may be willing to commit in a merchant line to partly or completely secure capital-intensive generation investment with long-term supply contracts outside their domestic area. Generator generally uses long-term supply contracts to secure capital-intensive generation investments (Roques et al., 2008) because the greater the fixed costs are, the greater the price and quantity risks are (Roques et al., 2005; Finon and Roques, 2008). Without long-term supply contracts, the investors are incentivized to choose less risky investments, even if they are more expensive (considering all the costs: investment, operational ones, etc.). This is why combined cycle gas turbines are particularly attractive to new entrants, which was confirmed by Watson (2004). With contractual arrangements and therefore less risk, the generation investors have better incentives to choose the optimal generation mix from the point of view of society. However, the EC's position regarding long-term supply contracts differs, especially for electricity incumbents who want to secure investments with long-term contracts in their own countries, because of the related risks of customer foreclosure (Hauteclocque, 2009a). Contracting abroad could thus be an alternative strategy and foreclosure effects would then be unlikely in most cases. Nonetheless, this strategy encounters a major obstacle as long-term supply contracts across borders would require parallel long-term priority access rights to interconnection, which are only available with a maximum duration of one year in the best case (ETSO, 2006). Even if the TSOs were willing to propose longer-term access rights, they could hardly do so without infringing upon the EU antitrust laws and the jurisprudence of the ECJ in VEMW (2005) where the Court came close to banning long-term priority access rights on interconnection (DG COMP, 2006; Hauteclocque, 2009b; Talus, 2005; Talus and Wälde, 2006). Therefore, the only way for generators to obtain long term access to interconnection is either to win an open season on a merchant line built by a TSO or to build their own merchant lines.

As a consequence, a positive effect of letting dominant generators obtain long term access to the network is not only that it facilitates investment and thus contributes to long-term generation adequacy, but that it may also contribute to fuel mix diversity by facilitating investments in base load technologies such as nuclear or coal. Overall, a better integration of policies regarding long-term supply contracts and MTI would enable European competition authorities to limit customer foreclosure, a major problem in European electricity markets, while facilitating the high fixed costs investments (both in transmission and generation) much needed for Europe's security of supply.

Two other benefits, which would also apply to MTI built by new entrant TSOs, must also be highlighted. First, for any transmission investment, an exempted investment is realized sooner than a regulated one (Gans and King, 2003, 2004). This is because in an uncertain environment it is hard for a regulator to commit to the long-term on the remuneration of a risky investment. The network operator anticipates this lack of commitment from the regulator and delays its investment until it is less risky. There is indeed less risk of regulatory hold-up with an exempted merchant line, though some risk always remains as acknowledged by the EC (DG TREN, 2009). By cancelling this delay, interconnection investment may be sunk sooner.

Second, allowing generators to invest in merchant lines creates competition for the development of the network. At the moment, incumbent TSOs are almost the only ones to invest in transmission 
capacity. Until now, they have never truly competed with each other but rather have cooperated in joint ventures. As a consequence, these investments are currently qualified as merchant investments because they do not rely on regulated revenue, not because there is competition to realize them. These investments, without any kind of competition, thus have a monopolistic dimension with regulatory holidays. In contrast, investments such as the one proposed by Imera ${ }^{23}$ between France and the United Kingdom bring real competition for investment in the network. Not only would the Imera line be in parallel to the existing France-England interconnector but in time it would also compete with the upgrade of the existing France-England interconnector by the French TSO RTE and the British TSO National Grid currently discussed. ${ }^{24}$ The interconnectors of the incumbent TSOs and of Imera are in a situation similar to pipe-to-pipe competition in the gas sector. They should thus compete to attract users by proposing the best transmission service (e.g. on access conditions-for instance there is a non-negligible access fee to the England-France interconnector jointly owned by RTE and National Grid, duration of transmission rights, platform for a secondary market of transmission rights, etc.) with the lowest price, thus increasing overall efficiency. Allowing generators to build MTI will thus increase these beneficial effects and increase the number of merchant investors, in particular with regard to the fact that they can raise capital more easily than pure new entrant TSOs.

Allowing MTI by dominant generators would yield significant benefits. The current dash for base-load generation investment also creates incentives for these generators to develop interconnection on a merchant basis and this should be seen as an opportunity. Letting weakly unbundled TSOs invest in merchant lines might under certain conditions be worse than the original problem of under-investment. The problem of pure new-entrant TSOs is different. They suffer the same problem of under-sizing but bring most of the benefits of merchant lines built by generators, especially competition for the network. When open seasons are introduced, pure new-entrant TSOs also enable generators to obtain long-term access rights to the network.

\subsection{Possible market abuse by dominant generators through MTI}

We previously emphasized the potential efficiency gains of letting dominant generators undertake MTI. However, it is fair to acknowledge that such investment opens new doors for market abuse, which can be classified into three broad categories.

The first type of market abuse concerns pre-emptive investment and anti-competitive retention of capacities. This relates to the idea that a dominant generator may be willing to build a merchant line for strategic reasons and not because it seeks to maximize profits under competitive conditions. Pre-emptive investment means that the dominant generator may build a merchant line so as to prevent a competitor from doing it first, with a view towards controlling cross-border capacities. ${ }^{25}$ Therefore a true first mover advantage exists in MTI if discretionary withholding of capacities is possible post-investment. This would be detrimental in particular when a MTI built by a generator forecloses a bigger line from being built. The risk of having a bigger line foreclosed is, or can be, limited in two ways. First, the main part of the analysis of the exemption request pursued by the regulators is a thorough analysis of the financial risk of the

\footnotetext{
${ }^{23}$ http://www.europagrid.com/EuropaGrid/EuropaGrid.html.

24 http://www.rte-rance.com/htm/fr/offre/telecharge/consultation_intecon nexions_2008.pdf.

${ }^{25}$ Of course, the risk of pre-emptive investment will decrease if high diseconomies of scale due to advances in merchant line technology occur in the future.
}

project. In theory, the regulators can grant an exemption only if the risk involved is such that the TSO would not undertake the project on a regulated basis. If the risk criterion is fulfilled, it is unlikely that another merchant project with a bigger size would proceed. This risk may indeed exist in some cases, but this has to be balanced with the benefits of having competition for transmission investment. Second, we note that the regulator can also limit this risk by consulting market participants. Any market participants that might be willing to invest in a bigger line later can then inform the regulator and help him to assess the risk of the investment currently being proposed. Even without any specific consultation by the regulator, market participants can now signal the risk of pre-emptive merchant investment during the consultation process associated to the Ten Year Network Development Plan (ENTSO-E, 2010a). ${ }^{26}$

The second competition problem may arise if the price differential between the home and the destination markets structurally reverses. In this case, the dominant generator may use the merchant line to block competitors importing from the former destination market. This then allows the dominant generator to protect its domestic market position in case it made a wrong investment decision in the first place. MTI in this case becomes a defensive investment ex post. Both problems amount to foreclosure of an essential facility.

The last competition problem relates to the opportunity given to the merchant line owner to manipulate wholesale spot prices in the destination market, especially during the peak period (Kuijlaars and Zwart, 2003). This will be possible if the size of the merchant line is substantial compared to the size of the destination spot market and if the merchant investor is already present as a major producer in the destination market.

Considering these possible market abuses, the benefits of MTI by dominant generators hold only if the related opportunities for market abuse can be mitigated. Indeed, "a positive competition assessment [in the case of dominant generators] is unlikely in the absence of conditions that effectively address the competition concerns" (DG TREN, 2009). The next section discusses these conditions and how they could be effectively implemented in the aftermath of the Third Energy Package.

\section{How to deter the anti-competitive use of MTI by dominant generators in the European institutional context?}

This last section proposes a suitable allocation of regulatory powers to deter potential anti-competitive conduct by dominant generators engaged in MTI. In this regard, the European context is interesting because it is a case of weak regulatory framework where a unique institution is unable both to monitor market power issues and to enforce remedies to anti-competitive behavior. Two institutions exercising separately these two tasks must then coordinate and combine their relative strength to ensure that the benefit from MTI built by dominant generators is maximized.

This section first shows that applying a Use-It-Or-Lose-It (thereafter UIOLI) mechanism could satisfactorily and quite easily mitigate potential competition problems as long as it is suitably monitored and enforced. This can be implemented in the European institutional context by relying on the strength of ACER and DG COMP, precisely the monitoring powers of ACER and on the antitrust powers of the EC.

${ }^{26}$ The Ten Year Network Development Plan (TYNDP) is issued by the association of European TSOs ENTSO-E (2010b) every two years to display a consolidated power network investment plan, including MTI. 


\subsection{Applying the UIOLI principle consistently}

From a technical point of view, the competition problems created by dominant generators controlling a merchant line arise from the possibility of the capacity owner not to exercise its rights. Hence, the key condition to mitigate these competition problems is to impose on the dominant generator a systematic UIOLI requirement, i.e., that when the owner of the merchant line does not use the line, it must then release the capacity to a secondary market. The key regulatory target here must be to ensure transparency, which means ensuring both reliable and timely access to information for potential users of the available capacity at different time horizons (ERGEG, 2010). Indeed, the foreclosure problems, namely pre-emptive investments, withholding of transmission capacities and defensive investments, all exist because the dominant generator has the possibility of not using the line. The risk of manipulation of wholesale prices in the destination market also arises from the fact that the dominant generator entirely controls the line. A strict application of the UIOLI principle would thus avoid an operator being able to limit the size of the daily available transmission capacity between two countries for anti-competitive reasons. It would also force the dominant operator to bear the full commercial risk of the investment and optimize the benefit for society when price differentials reverse. Even if a cap on the capacity owned by a dominant generator on a new merchant investment had a similar mitigation effect, ${ }^{27}$ a UIOLI provision would fulfill it either way and would likely have a lesser impact on the investment decision ex ante, especially on its size. Indeed, a cap would lead to revenue uncertainty on the remaining capacities, which would limit incentives to invest. In the case of an association of collectively dominant producers, opportunities for collusion and the market abuses depicted above are higher (Joskow and Tirole, 2000; DG TREN, 2009). The UIOLI provision is thus even more important in this case.

As demonstrated by Sauma and Oren (2009), efficiency for individual market players and efficiency for society converge far more than regulatory authorities tend to think in the case of merchant lines developed by dominant producers. However, we do not argue in favor of a complete laissez-faire with no ex ante regulation or antitrust enforcement whatsoever. To the opposite, regulation must be tailored to this specific case and the required tools already exist. The UIOLI provision has indeed been applied in different contexts, for instance at the French-Belgian and Dutch-Belgian borders, and now needs to be applied more consistently. However, the monitoring of compliance with this provision may be problematic because the regulatory framework is especially weak on cross-border issues. The problem of enforcement will thus be crucial. The next section shows that the new characteristics of the regulatory framework after implementation of the Third Energy Package in fact allows for a satisfactory mitigation of competition problems.

\subsection{A new allocation of regulatory powers}

The imposition of a UIOLI mechanism requires both the constant monitoring of transparency requirements and a light

\footnotetext{
${ }^{27}$ Note that imposing a cap seems to become the preferred way to limit abuses of dominance when granting exemptions (DG TREN, 2009). In Italy, for instance, a very stringent cap of $20 \%$ has been imposed in the past. In the case of Nabucco, a $50 \%$ cap has been imposed for the allocation of capacity to any firms that are dominant in the upstream or the downstream natural gas markets, as for the Dutch LNG terminal Gate. Finally, in the East West Cable the cap was 70\%, except for the Irish incumbent ESB, which had a cap of $40 \%$. If these caps were to be generalized, the incentives of some major market players to invest in merchant lines would thus diminish.
}

deterrence-based mechanism to trigger self-enforcement. Indeed, the threat of exemption removal in the case of non-compliance might not be sufficient to deter anti-competitive behaviors. An efficient regulatory framework for MTI could thus be based on two pillars that would take into account the respective strengths and weaknesses of the different entities in charge of the regulation of European energy markets following the enactment of the Third Energy Package.

The first pillar could be the monitoring of transparency requirements by ACER. The monitoring of the UIOLI provision might be ensured by NRAs, but having a unique body at the community level would facilitate its implementation. However, there is a need to examine whether ACER can effectively be used with such broad-ranging monitoring powers.

ACER, like most European agencies, does not dispose of final decision-making powers. ${ }^{28}$ This limitation is primarily based on the so-called Meroni doctrine (named after the Meroni case in the late 1950s), which defines the conditions under which regulatory powers can be granted to a new EU agency. The Meroni doctrine postulates that an institution like the EC cannot delegate to an agency powers it itself does not possess. ${ }^{29}$ Moreover, not all powers can be delegated. Only strictly defined execution powers can be delegated. Political or decision-making powers cannot then be delegated. This implies that the delegating entity must conserve the decision-making powers and strictly monitor the powers of the agency. The problem then becomes to differentiate between technical and truly political powers. The monitoring of transparency requirements is most likely to be considered a technical issue in the sense of Meroni. Indeed, technical decisions under the Meroni doctrine include specialized issues that follow clearly defined goals and exclude any balancing between conflicting political objectives, which is most likely to be the case of the monitoring of transparency requirements. The monitoring of transparency requirements in the case of MTI could actually be based on Art 11(1) of the new Regulation 713/2009 on crossborder exchanges which clearly states that: "The Agency [ACER], in close cooperation with the Commission, the Member States and the relevant national authorities including the national regulatory authorities and without prejudice to the competences of competition authorities, shall monitor the internal markets in electricity and natural gas, in particular the retail prices of electricity and natural gas, access to the network including access of electricity produced from renewable energy sources, and compliance with the consumer rights laid down in Directive 2009/72/EC and Directive 2009/73/ $E C^{\prime}$ [emphasis added]. ${ }^{30}$

A public report could then be published pursuant to Art. 11(2), even though it should comply with confidentiality requirements. To make the monitoring by ACER easier and more legitimate, the EC could adopt guidelines to specifically define the technicalities of the monitoring duty and give the power to ACER to decide whether the UIOLI principle has been complied with or not. To avoid any legal uncertainty, we see much advantage in having the EC providing guidelines on duration, capacity allocation and the organization of secondary capacity trading. This would allow potential users to effectively use free capacities and a secondary

${ }^{28}$ We recall that even for the grant of exemptions, the EC or Member States retain the final decision power over ACER under certain conditions.

${ }^{29}$ The doctrine also states that an institution cannot delegate to an agency wide discretionary powers because this would be a breach of the institutional balance, i.e. that it would modify the balance of powers between the different EU institutions (EC, Parliament, Council, etc.). The powers delegated can therefore be neither greater nor different than those granted in the first place by the EU Treaty.

${ }^{30}$ Recital 8 also states that "the Agency should monitor, in cooperation with the Commission, the Member States and relevant national authorities, the internal markets in electricity and natural gas and inform the European Parliament, the Commission and national authorities of its findings where appropriate". 
market to develop (see, e.g., the discussion in EFET, 2002, for gas). What would constitute an objective justification for capacity withholding will also have to be defined, keeping in mind that transmission assets are usually more reliable than generation assets.

With regard to this objective, the Market Monitoring Units of the ISOs/RTOs in the USA give extensive examples of relevant indicators to ensure that the transmission markets behave in a competitive manner (Twomey et al., 2005). From these good practices, one would expect that ACER monitors four types of indicators. First, monitoring energy prices at both ends of the line, ACER could ensure that the MTI capacity fully exploits any arbitrage between the energy markets at both ends, i.e. that transmission capacity is not withheld. The second indicator concerns the performance of the secondary market for the released transmission rights (in case the owner does not use them). Comparing the difference between the price of released transmission rights and the energy price differential, the regulator could ensure that the transmission right market behaves efficiently compared to the energy markets. The third interesting indicator is the concentration of the transmission right market for the considered MTI, so that the regulator could focus on dominant positions and potential market abuses in the secondary market. The last indicator monitors whether market participants manipulate price and quantity. The regulator could then track any situation where a MTI owner's subsidiary or sister-company systematically acquires transmission rights on the secondary market (for instance bidding at very high price), then foreclosing the secondary markets to any true competitors of the MTI owner.

The second pillar could be based on the antitrust powers of the EC to fight abuses of a dominant position. Indeed, the fact that an exemption has been granted does not restrict the application of EU antitrust law (DG TREN, 2004), as is the case for any European sector-specific legislation or national regulatory action (Geradin, 2004/2005; Gatto, 2006). It has been emphatically recalled in the recent Deutsche Telekom cases. The Deutsche Telekom case concerned the prices charged by Deutsche Telekom to competitors for accessing the local loop. As these prices exceeded those charged to the subscribers of Deutsche Telekom on the retail market, the EC considered that the Deutsche Telekom pricing strategy could be analyzed as a margin squeeze. The German incumbent argued that its prices to competitors could not be in breach of Art 102 TFEU (the EU Treaty article on the abuse of a dominant position) because the German regulator had previously approved its tariff scheme. The EC, however, dismissed this argument and considered that the responsibility of Deutsche Telekom was engaged in view of the superiority of Article 102 TFEU over secondary EU law in the hierarchy of European rules. From an antitrust perspective, granting exemptions to market operators dominant in related markets, however, raises two questions. First, does it infringe EU antitrust law per se? This is a problem for potential investors who would face the risk of infringing EU law. Second, is EU antitrust law able to fix the problem in case of non-compliance with the UIOLI condition? The answer is positive in both cases.

Allowing MTI by dominant generators would indeed create a position of dominance on the cross-border transmission market, provided a merchant line effectively constitutes the relevant market on its own, which appears to be the case (see the UK-French interconnector case and Talus and Wälde, 2006). However, dominance per se is not banned under EU antitrust law, especially in a case where efficiency gains in terms of increased investment and greater market integration are involved, which as we saw is the case here. Increased investment, transparency and a secondary capacity trading platform seem to be the three key conditions for compliance with EU antitrust law when it comes to interconnectors (Hauteclocque, 2009b). Therefore dominant generators will not face the risk of uncertain application of EU antitrust law as long as they respect the conditions imposed, i.e., a UIOLI mechanism. ${ }^{31}$

However, non-compliance with the UIOLI principle would constitute an unlawful abuse of dominance and would be qualified as a refusal to deal or as excessive pricing. Indeed, retention of transmission capacities will naturally qualify as a refusal to deal but the setting up of excessive prices for the unused capacity may de facto create the same exclusionary effects. Similarly, if the imported electricity is offered at too high a price in the destination market, the lack of demand will also result in capacity withholding in practice.

Price issues are never easy to deal with under antitrust law but European competition authorities are building expertise on this issue, as has been seen in the German wholesale market where E.ON was obliged to commit to divest $4800 \mathrm{MW}$ of generation capacities to address capacity withholding concerns. In addition, the deterrence effect of EU antitrust law should offset this weakness. Indeed, if antitrust law is not perfectly equipped to deal with issues such as possible network externalities, which should thus be left to sector-specific regulation, its ability to sanction should be relied on. The EC can and does impose heavy fines, ${ }^{32}$ up to $10 \%$ of a company's total revenues, which is increasingly ensuring a strong deterrence effect. The recent E.ON and RWE settlements have also shown that dominant generators prefer bargaining satisfactory solutions with the EC than going through an uncertain and potentially very costly court trial.

Recently, the allocation of energy regulatory powers in the European Union has been increasingly biased in favor of the ex post enforcement of EU antitrust law (Hauteclocque and Glachant, 2009). The EC should thus clearly and publicly state that it will enforce EU antitrust law in the case of non-compliance with the UIOLI condition. Finally, allocating transparency monitoring to ACER would also provide more reliable proofs to ground an infringement of EU antitrust law in the case of court trial, especially if objective technical or business justification for capacity withholding were previously defined in EC guidelines.

The strict imposition of the UIOLI principle, coupled with a smart allocation of regulatory powers seems the best way to go forward with the development of MTI. This solution shows that complementarities must and can be found between the ex ante and ex post parts of the European regulatory framework for energy.

\section{Conclusion}

A new model for the regulation of MTI in Europe should take into account the opportunities brought up by the changes in both the energy mix of Member States and the evolution of regulatory tools. The EU should now clearly allow MTI by dominant generators and implement an enforcement regime based on a clear demarcation between transparency monitoring by ACER and antitrust enforcement by the EC. We submit that even if some doubts remain on the practical implementation of the UIOLI principle, the wider benefits in terms of investments (both in

\footnotetext{
31 The only case where EU antitrust law could be infringed seems to be when there are several promoters for the infrastructure that jointly market the capacity, without prior open season. Another problem may lie in the possible coordination (collusion) in the related markets of two generators jointly investing in a merchant line.

${ }^{32}$ Highly representative of this was when the European Commission imposed a fine on E.ON of 38 million euros for the breach of a seal in E.ON's premises during an inspection.
} 
transmission and generation) and the urgency of the situation require a bolder approach.

Having a more integrated approach to competition policy, in order to leverage the complementarities between ACER and the antitrust powers of the EC, appears to be a way to bring a new impetus to interconnection investment in Europe. Similarly, a better integration of policies on long-term supply contracts and MTI would enable European competition authorities to limit customer foreclosure (a major problem in European electricity markets) while facilitating the high fixed costs generation investments sorely needed for the security of supply of Europe. It is true that allowing MTI by dominant generators indeed means creating a position of dominance in the cross-border transmission markets. But as long as potential market abuses can be mitigated this is an acceptable improvement of regulation and probably the best way today to regulate MTI. Europe could then become an interesting model for countries willing to push for MTI despite a weak regulatory framework.

\section{References}

Bushnell, J., Stoft, S., 1996. Electric grid investment under a contract network regime. Journal of Regulatory Economics 10 (1), 61-79.

Brunekreeft, G., 2005. Regulatory issues in merchant transmission investment. Utilities Policy 13 (1), 175-186.

Brunekreeft, G., Neuhoff, K., Newbery, D., 2005. Electricity transmission: an overview of the current debate. Utilities Policy 13 (2), 73-93.

Brunekreeft, G., Newbery, D., 2006. Should merchant transmission investment be subject to a must-offer provision? Journal of Regulatory Economics 30 (6), 233-260.

Cariello, F., 2008. The Italian Electricity Market. AEEG, 6 October. Available at: 〈http://www.industrie.gov.tn/fr/projetelmed/images/pdf/10_Italian_market. pdf $>$.

CRE, 2008. Investigation by CRE into Record High Electricity Prices on Powernext Day-ahead Auction in October and November 2007. Analysis Report. 17 April 2008. Available at: 〈http://www.cre.fr/en/content/download/5585/121887/ file/080417_AnalysisReport.pdf $\rangle$.

CRE, 2009. Conclusions of the French Energy Regulatory Commission (CRE) on the Spike in Electricity Prices on 19 October 2009. 20 November 2009. Available at: 〈http://www.cre.fr/en/content/download/9217/159794/file/091120_Com municationPicPrix_en.pdf $\rangle$.

CRE, 2010. Public consultation by the French Energy Regulatory Commission, Commission de Régulation de l'Energie of May 3, 2010 on the Enforcement of Article 7 of Regulation (EC) no. 1228/2003 of June 26, 2003 and on Conditions for Access to the French Electricity Transmission Grid for New Exempt Interconnectors.

DG COMP, 2006. Commission Staff Working Paper on Decision C-17/03 of June 7, 2005 of the Court of Justice of the European Communities. SEC 2006, 547.

DG COMP, 2007. DG Competition Report on Energy Sector Inquiry. SEC 2006, 1724 final.

DG TREN, 2004. Note of Interpretation on Directives 2003/54-55 and Regulation $1228 / 03$ in the Electricity and Gas Internal Market: Exemptions from Certain Provisions of the Third Party Access Regime.

DG TREN, 2008. Towards a Secure, Sustainable and Competitive European Energy Network. $\operatorname{COM}(2008) 782$ final.

DG TREN, 2009. Commission Staff Working Document on Article 22 of Directive 2003/55/EC Concerning Common Rules for the Internal Energy Market in Natural Gas and Article 7 of Regulation (EC) No 1228/2003 on Conditions for Access to the Network for Cross-border Exchanges in Electricity-New Infrastructure Exemptions. SEC(2009) 642 final.

Edwards, N., 2010. Merchant Investment in Electricity Interconnection. EU Energy Law and Policy Workshop. Investment, Financing and Regulatory Framework for Cross-border Infrastructures: Law and Policy Perspectives. Florence. November 12. 〈http://www.florence-school.eu/portal/page/portal/FSR_HOME/ ENERGY/Policy_Events/Workshops/2010/Crossborder_Infrastructures/ 101112_Nigel_Edwards.pdf $>$.

Energy Information Administration (EIA), 2011. Annual Energy Outlook 2011. Available at:〈http://www.eia.gov/forecasts/aeo/pdf/0383(2011).pdf 〉.

EFET, 2002. Use-it-or-lose-it principles.

ENTSO-E, 2010a. TYNDP Public Consultation. Report on received comments. May 21. 〈https://www.entsoe.eu/fileadmin/user_upload/_library/SDC/TYNDP/ Report_Answers_on_Consultation.pdf $>$.

ENTSO-E, 2010b. Ten-Year Network Development Plan 2010-2020. June 28. <https://www.entsoe.eu/fileadmin/user_upload/_library/SDC/TYNDP/TYNDPfinal_document.pdf $\rangle$.

ERGEG, 2007a. Treatment of New Infrastructure: European Regulators' Experience with Art. 22 Exemptions of Directive 2003/55/EC. Ref: E07-TNI-01-04.

ERGEG, 2007b. Guidelines for Good Practices on Open Season Procedures. Ref: C06-GWG-29-05c.
ERGEG, 2010. Comitology Guidelines on Fundamental Electricity Data Transparency. Ref: E10-ENM-27-03.

ETSO, 2006. An Overview of Current Cross-border Congestion Management Methods in Europe.

Finon, D., Roques, F., 2008. Financing arrangements and industrial organization for new nuclear build in electricity markets. Competition and Regulation in Network Industries 3, 247-282.

Gans, J.S., King, S.P., 2003. Access holidays for network infrastructure investment. Agenda $10(2), 163-178$.

Gans, J.S., King, S.P., 2004. Access holidays and the timing of infrastructure investment. Economic Record 80, 89-100.

Gatto, A., 2006. Governance in the European Union: a legal perspective. Columbia Journal of European Law 12 (2), 487-516.

Gence-Creux C., 2010. Is There a Role for Merchant Lines in the Development of Interconnections? EU Energy Law and Policy Workshop. Investment, Financing and Regulatory Framework for Cross-border Infrastructures: Law and Policy Perspectives. Florence, November 12. 〈http://www.florence-school.eu/portal/ page/portal/FSR_HOME/ENERGY/Policy_Events/Workshops/2010/Crossborder_Infrastructures/101112_Gence-Creux.pdf $>$.

Geradin, D., 2004/2005. The development of European regulatory agencies: what the EU should learn from American experience. Columbia Journal of European Law 11 (1), 1-52.

Hauteclocque, A.de, 2009a. Legal uncertainty and competition policy in European deregulated electricity markets: the case of long-term exclusive supply contracts. World Competition 32 (1), 91-112.

Hauteclocque, A.de, 2009b. Long-term Supply Contracts in European Decentralized Electricity Markets: An Antitrust Perspective. Ph.D. Thesis, University of Manchester School of Law.

Hauteclocque, A.de, Glachant, J-M., 2009. Long-term supply contracts in European competition policy: fuzzy not crazy. Energy Policy 37 (12), 5399-5400.

Hogan, W., 1992. Contract networks for electric power transmission. Journal of Regulatory Economics 4 (3), 211-242.

Hogan W., 2002. Financial Transmission Incentives: Applications Beyond Hedging. Working Paper Harvard Electricity Policy Group.

Henry, C., 1997. Concurrence et services publics dans l'Union Européenne. Presses Universitaires de France, Paris.

Henry, C., Matheu, M., Jeunemaitre, A., 2001. Regulation of Network Utilities: The European Experience. Oxford University Press.

Joskow, P., 2006. Patterns of transmission investment. In: Lévêque, F. (Ed.), Competitive Electricity Markets and SustainabilityEdward Elgar, Cheltenham, UK, pp. 131-186

Joskow, P., Tirole, J., 2000. Transmission rights and market power on electric power networks. RAND Journal of Economics 31, 450-487.

Kuijlaars, K-J., Zwart, G., 2003. Regulatory Issues Surrounding Merchant Interconnection. Dienst uitvoering en Toezicht Energie (Office for energy regulation), The Netherlands.

Littlechild, S., 2003. Regulated and Merchant Interconnectors in Australia: SNI and Murraylink Revisited. CMI Working Paper 37, University of Cambridge.

Meade R., 2005. Ownership vs. regulation in electricyt reform: the role of governance. In: Conference "The European Electricity Market, EEM-05", 10-12 May, Lodz, Poland.

NG, 2010. Consultation Document GB ECM-26: Review of Interconnector Charging Arrangements.

Nyssens, H., Schnichels, F., 2007. Energy. In: Faull, J., Nikpay, A. (Eds.), The EC Law of Competition 2nd ed. Oxford University Press, Oxford, pp. 1361-1463.

Piebalgs, A., 2008. Energy security in the Baltic Sea region. Speech at the Baltic Sea Regional Business Forum, 3 June.

Roques, F., Newbery, D.M., Nuttal, W.J., 2005. Investment incentives and electricity market design: the British experience. Review of Network Economics 4 (2), 93-128.

Roques, F.A., Newbery, D.M., Nuttall, W.J., 2008. Fuel mix diversification incentives in liberalized electricity markets: a mean-variance portfolio theory approach. Energy Economics 30 (4), 1831-1849.

Sauma, E.E., Oren, S.S., 2009. Do generation firms in restructured electricity markets have incentives to support social-welfare-improving transmission investments? Energy Economics 31 (5), 676-689.

Stoft, S., 2006. Problems of transmission investment in a deregulated power market. In: Lévêque, F. (Ed.), Competitive Electricity Markets and SustainabilityEdward Elgar, Cheltenham, UK, pp. 87-130

Talus, K., 2005. First experience under the exemption regime of EC Regulation $1228 / 2003$ on conditions for access to the network on cross border exchanges in electricity. Journal of Energy and Natural Resources Law 25 (3), 266-281.

Talus, K., 2006. First interpretation of energy market Directives by European Court of Justice-Case C-17/03, Vereniging vooe Energie. Journal of Energy and Natural Resources Law 24 (39), 39-52.

Talus, K., Wälde, T., 2006. Electricity interconnectors: a serious challenge for EC competition law. Competition and Regulation in Network Industries 1 (3), 353-387.

Twomey, P., Green, R., Neuhoff, K., Newbery, D., 2005. A Review of the Monitoring of Market Power: The Possible Roles of TSOs in Monitoring for Market Power Issues in Congested Transmission Systems. Working Papers 0502, Massachusetts Institute of Technology, Center for Energy and Environmental Policy Research. 〈http://tisiphone.mit.edu/RePEc/mee/wpaper/2005-002.pdf 〉.

Watson, J., 2004. Selection environments, flexibility and the success of the gas turbine. Research Policy 33, 1065-1080. 